\title{
Asymmetric Information and Volatility of Stock Returns in Nigeria
}

\author{
Joshua Odutola Omokehinde ${ }^{1 *}$, Matthew Adeolu Abata², \\ Russell Olukayode Christopher Somoye ${ }^{1}$, Stephen Oseko Migiro ${ }^{2}$ \\ ${ }^{1}$ Olabisi Onabanjo University, Ago Iwoye, Nigeria \\ ${ }^{2}$ University of KwaZulu-Natal, Durban, South Africa \\ joshuaomokehinde57gmail.com*, abatam@ukzn.ac.za, olukayodesomoye@hotmail.com,migiro@ukzn.ac.za
}

\begin{abstract}
This paper investigates the effect of asymmetric information on volatility of stock returns in Nigeria using the best-fit Asymmetric Power Autoregressive Conditional Heteroskedasticity, APARCH $(1,1)$ model, under the Generalized Error Distribution (GED) at 1\% significance level from 3 January 2000 to 29 November 2016. The descriptive statistical results showed that the returns were not normally and linearly distributed, with strong evidence of a heteroskedasticity effect. The results of the analysis also confirmed the effect of asymmetric information on the volatility of stock returns in the Nigerian stock market. The asymmetric parameter $(\gamma)$ was negative at $(-1.00)$, which is statistically significant at $1 \%$ level. This confirms that there is an asymmetric or leverage effect where bad news had a more destabilizing effect on the volatility of stock returns than good news. The total impact of bad news on volatility was explosive at 2.0, during the period under review. Also, the volatility persistence which is measured by the sum of $\operatorname{ARCH}(\alpha)$ and GARCH( $\beta)$ stood at 1.695950 . This is above unity and suggests that volatility takes a long time to attenuate in Nigeria. This could be largely ascribed to the persistent effect of the 2008 global financial crisis, which probably eroded investors' confidence in the market.
\end{abstract}

Keywords: Asymmetric Information, Volatility, Asymmetric Power Autoregressive Conditional Heteroskedasticity, Generalized Error Distribution, Volatility Persistence

\section{Introduction}

Information is a key driver of stock returns and volatility in the equity market. This information can be idiosyncratic and macroeconomic in the form of cross-sectional and time series. Generally, information comes to the market on scheduled (with prior notice of the date and time of release) or unanticipated (without notice). Information also enters the market linearly (symmetrically) or non-linearly (asymmetrically). The information can also be bad (negative) and good (positive) news with serious implications for the volatility of stock returns. The response of stock prices to information is used in this study as metrics to measure whether a stock market is symmetric or asymmetric. If the response of equity prices is to fully reflect available information without giving rise to mispricing, where investors have homogenous expectations of the distribution of stock returns and volatility and are privileged to information at the same time, and where the market price of an equity is equivalent to its intrinsic value, where investors have full knowledge of the opportunity set available to them, and nobody is privileged to explore information to profit at the expense of others in the market, then, the market is perfect or efficient or informational symmetric. Conversely, the market is informational asymmetric when there are disparities between the intrinsic and market values of financial instruments, and where investors' expectations about the probability distribution of expected returns and risks is heterogeneous. It is a situation where one party to a transaction is privileged to explore information unknown to the other party as opportunity to profit at the expense of the under-informed investors. Stiglitz (2003) defines information asymmetry as "the condition where some information is known to some, but not to all parties involved" in a transaction, and consequently cause the market to become inefficient. Stiglitz and Walsh (2002) also posit that prices and markets provide the basis of the economy's incentive system. But there are some information problems that markets do not handle, or do not handle well. The imperfect information sometimes inhibits the ability of the market to perform the tasks it performs so well, when information is complete.

In an efficient market, investors act rationally and prices of shares fully reflect all available information spontaneously. It is not possible for investors to consistently beat the market on a risk-adjusted returns basis. Fama (1970) propounded efficient market hypothesis (EMH) and further assumed that agents have rational expectations; that on average the population is correct and whenever new relevant information filters into the market, the agents update their expectations appropriately. The theory is based on the Gauss (1821) 
classical linear regression model. Under this theory, trading in shares does not attract any transaction cost, no taxes and all participants have homogeneous expectations of the distribution of expected returns with equal access to information at the same time. The investment strategy best suited for this market is the "buy-andhold" (passive) strategy. The reactions of investors are assumed to be random and to follow a normal Gaussian distribution pattern, so that the net effect on stock market returns is negligible for an abnormal profit. The returns distribution in the market is characterised with linearity, non- serial correlation, independent and identically distribution of stock returns, with zero mean and constant variance of error term (homoscedastic). The classical theory only considered the first and second moments of unconditional mean and variability of stock returns in linearity (symmetric) form. The third and fourth moments for normal distribution of returns measured by skewedness and kurtosis are (0) and (3) respectively. Further to the normal distribution behavior of stock returns, the classical economist failed to consider other statistical distributions of financial time series like Student's t, Generalized Error Distribution (GED) and Skewed Student's t-Distribution. Another behavior of stock returns under the classical linear regression model is that past and current returns are mutually exclusive. There are no serial correlations between current returns and $\left(R_{t}\right)$ and past returns $\left(R_{t-1}\right)$. This is in consistent with the Random Walk theory of Kendall (1953), which states that successive stock returns are not statistically associated.

Over recent years, the impact of information on the returns of equity markets has received considerable attention in the academic literature. An appropriate method of characterizing and summarizing the behavior of stock returns is to describe them in terms of their distribution function. The normality distribution of stock returns is questionable if macroeconomic news does not arrive linearly to the market or even if it does, if investors do not react linearly to its arrival. In both cases, assumptions for market efficiency may fail if the standard regression treats the market reaction to the same type of information as being identical (symmetric) at all time. In reality, the market, seems to treat otherwise similar information differently (asymmetrically), where there are possibilities for equity mispricing or profit opportunities. A market is informational asymmetric where prices of securities exhibit volatility clustering with large changes tend to be followed by large changes of either sign or small changes tend to be followed by small changes (Mandelbrot, 1963) within a short period of time for a given set of returns. A market, where successive stock returns are statistically correlated, and are not independently identically distributed, but asymmetrically distributed through Student's t, Generalized Error Distribution (GED) and Skewed Distribution. If an equity market is informational symmetric, then, security screening, allocation or selection and the role of professional managers is less important for investors, and it would be better to just buy a large basket of stocks and following a passive investment strategy with a view to buying and holding, and thereby reducing churning and minimizing transaction costs.

In reality, the unfolding events in the financial world economies violated some of the rules of the market efficiency; like the "buy-and-hold" investment strategy. Investors who followed this style always become victims whenever the market crashes. Adopting a passive investment strategy has been challenged especially during the global economic meltdown of 2008 or when there is a market crash such as in the US stock market. The use of the symmetry ARCH model by Engle (1982) and the GARCH model by Bollerslev (1986) to measure the effect of information on stock returns, is limited because: (i) the variance of the models is linear functions of the lagged squared residuals and the residual innovations; (ii) it has a conditional variance that only depend on the size or magnitude of the shocks i.e. lagged error, not the sign. It means that both negative and positive news have the same impact on future volatility of the same magnitude. The homoscedasticity assumption by the classicalists that the expected value of all error terms, when squared, is the same at any given point is no longer tenable in reality. A striking feature of the return series is volatility clustering. Several econometric models on changing conditional variance have been developed to test and measure volatility clustering. In modern financial literature, a number of stylized facts about the volatility of financial asset prices have emerged over the years, and have been confirmed in several studies e.g. that the variance of asset returns is not constant but time-varying (Engle, 1982; Bollerslev, 1986; Nelson, 1991). Asset prices are characterized by volatility clustering (Mandelbrot, 1963).

The GARCH model of Bollerslev (1986) gives parsimonious models that are easy to estimate and, even in its simplest form, has proven surprisingly successful in predicting conditional variance. This is a great improvement on Engle's (1982) GARCH model. There are different versions of GARCH models: from the 
simplest and most robust of the family of volatility like the GARCH $(1,1)$ model, through to sophisticated ones like EGARCH, GJR-GARCH, APAGARCH, and GARCH-M. Although, the GARCH model has proven to be useful in capturing the symmetric effect of volatility, it is believed with some limitations, such as the violation of nonnegativity constraints imposed on the parameters to be estimated. The original GARCH model can be modified and extended in many ways to overcome these constraints to capture asymmetry effects using Threshold GARCH (TGARCG) proposed by Zakoian (1994), EGARCH by Nelson (1991), the GJR-GARCH model by Glosten, Jagannathan, and Runkle (1993), and the Asymmetric Power ARCH (APARCH) by Ding, Granger, and Engle (1993). The tenet of the proponents is that good and bad news of the same magnitude have differing effects on the conditional variance. Thus, it was found that Nigeria operates an informational weakform efficient market as documented by Ayadi (1984), where not everyone has access to the same news, nor does everyone receive the news in a timely fashion (Strong, 2004). Information asymmetry has a wider application in research especially in the financial literature. The pervasive effects of information asymmetry in the market have been documented and studied in numerous contexts. However, for the purpose of this study, it will be examined in the context of the effects of asymmetric information on volatility of stock returns. The objective of this paper is to investigate the effect of asymmetric information on the volatility of stock returns in Nigeria. This has important implications for pricing financial assets, portfolio selection, and risk management. Market regulators will also find the results useful in terms of making rules to reduce asymmetry information by ensuring uninterrupted flow of information in the market. The paper is structured into four sections: Literature Review, Methodology, Empirical Results, and Summary and Discussion.

\section{Literature Review}

The distribution of information between economic agents accounts for the increase in the level of adverse selection effect and exacerbates the ask-bid spread (returns). The theory underpinning asymmetric information relative to the behavior of stock returns is rooted in the classical theory of finance based on the Gauss (1821) assumptions that gave birth to the Random Walk Theory espoused by Kendall (1953), the Modern Portfolio Theory by Markowitz (1952), the Capital Asset Pricing Model by Sharpe (1964), and Lintner (1965), the Efficient Market Hypothesis by Fama (1970); the Arbitrage Pricing Theory by Ross (1976); and other multi factors index models. The capital market theories are based on perfect market where information is symmetric and investors have homogenous expectations about the distribution of returns, equity prices fully reflect available information, there are no abnormal profit opportunities, no transaction costs, the investment strategy is passive ("buy-and-hold"), and no participant is more privileged to information than others. In addition, the variance of error term is constant with zero mean. The distribution of returns is normal where the maximum kurtosis is 3.0, and returns distribution is independent identically distributed, and mutually exclusive of past and present prices; prices are not auto-correlated but rather linearly dependent.

There are some challenges as to the practice of the above theories, especially in application to financial time series data. First, the controversies as to how many risk factors are to be included are still subjective today. While Sharpe (1964) used the single index factor, Ross (1976), Chen, Roll, and Ross (1986), and Fama \& French (1993) used multiple factors. However, the researchers used beta as a risk coefficient. While the proponents of CAPM used a single beta to measure the risk factor, others used multiple betas, each for different factors to measure the risk. Unlike the CAPM where macroeconomic variables (systematic risk) are accounted as the only factor influencing stock returns while the company-specific factor (unsystematic risk) is assumed to be completely diversified, the multi-factor models attributed the behavior of stock returns to macroeconomic and company-specific factors. The Fama \& French (1993) factor model argue that the variability in common stocks returns is explained not only by market risk as espoused by Sharpe (1964) but also by factors related to size, and book-to-market ratio. More recently, Fama \& French (2015) extended the model by adding a further two factors: profitability and investment. MSCI BARRA (2013) listed six risk premier factors influencing stock returns: size (low size), book-to-market ratio (value), low volatility, high yield, quality, and momentum. A search for the appropriate factors that may influence asset returns, risk, covariance, and volatility is yet unending. There is no specific consensus on the number of factors required to adequately explain the effect of the factors on stock returns and volatility. 
Researchers however began to model stock market returns jointly with their conditional volatility, acknowledging that the impact of idiosyncratic and macroeconomic variables on equity returns is neither time-invariant nor linear. Wold's (1939) Decomposition theory establishes that a financial time series has two unrelated components: deterministic and stochastic processes. The two processes are combined to form an Autoregressive Moving Average (ARMA). The error term also has two components: time-variant and timeinvariant. The time-variant is conditional variance while the time-invariant is unconditional variance. Engle (1982) expressed the conditional variance as a linear function of past squared disturbances in order to develop his Autoregressive Conditional Heteroskedasticity (ARCH) model. Several parameters and a high order q to capture the volatility process and the assumption of zero weight for observations more than one month old motivated Bollerslev (1986) to generalized ARCH to include the ARMA structure known as GARCH parameterization in order to remedy the lacuna in the ARCH model. The GARCH model was based on an infinite ARCH specification to reduce the number of estimated parameters, by imposing non-linear restrictions (Alberg, Shalit, \& Yosef, 2008). GARCH is a linear function of past squared innovations and lagged squared variance and account for volatility clustering. Both the ARCH and GARCH models allow bad and good news to have an equal impact on volatility, but fail to capture the leverage effect.

The failure of GARCH to capture asymmetric or leverage effect in financial time series volatility led to the development of several higher and more sophisticated GARCH models. Unlike GARCH models, they are nonlinear functions of the exogenous variables but rather exponential and quadratic functions. Nelson (1991) developed the Exponential GARCH (EGARCH) model while Glosten, Jagannathan, and Runkle (1993) also developed the GJR-GARCH models to capture the leverage effect. Some of the models in this category include Threshold GARCH (TGARCH) by Zakoain (1994), and Asymmetric Power ARCH (APARCH) by Ding, Granger, and Engle (1993). The models allow bad news and good news to have different impact on volatility in a nonlinear formulation. Negative shocks tend to have a higher effect on volatility than positive news. Thus, the behavior of financial time series is best described as a reflective of an asymmetric informational market where the investors' expectations are heterogeneous, stock returns distribution are not normal but of Student's t, GED, and Skewed Student's t. A market where past and present returns are mutually inclusive (autocorrelation), the variance of error term is time-variant, return is non-linear dependent, where the third and fourth moments measured by skewedness and kurtosis are important in the determination of the statistic characteristics of time series. While skewedness measures the degree of asymmetry of the distribution of returns around its mean, kurtosis measures the "fatness" of the tails of a return distribution. Similarly, in a market where the distribution of return is normal, skewedness is zero, and kurtosis is 3.0(mesokurtic). However, when the kurtosis is greater than 3.0, stock return is leptokurtic or fat-tailed or heavy-tailed. Conversely, when the skewedness is greater or less than zero, stock return distribution is asymptotic. Thus, in a financial time series, the best model to be applied is the GARCH family that exhibits the above statistical characteristics. In view of the controversies surrounding the factors affecting the behavior of stock returns, this paper will focus on market index series, which can be used to evaluate and distribute stock behavior into: returns, size, and volatility and will empirically conclude whether there is presence or absence of asymmetric information in the Nigerian stock exchange and what the effect is on the volatility of stock returns.

Empirical Reviews: Akerlof (1970) was the first to analyze the impact of information asymmetry in any market. He used the US market for used cars where the old and faulty cars are known as "lemons". He found the presence of information asymmetry in the car market was characterized by the informational level of the agents, where the car sellers are more privileged to information about the condition of the cars than the buyers, and hence they explored this privilege information to make more profit at the expense of the underinformed buyers. Easley and O'Hara (2004) found a positive correlation between information asymmetry and stock returns, where good news reduces volatility and boosts returns. Wang et al., (2005) also examine the relationship between the behavior of stock returns, volatility of stock returns (risk) and volume of trading (used as a measure of information access) and found a positive effect of the trading volume on stock returns. Depending on the level of information of Abad and Rubia (2005) state that the financial market recognizes two types of investors: informed and uninformed (less informed) agents. They found that informed agents used privilege information to obtain economic gains without justifying the fundamental value of the asset price, while uninformed agents trade for liquidity purposes only relying on public information and their personal convictions. Clarke and Shastri (2000); and Levi and Zhang, (2008) found a positive correlation 
between information asymmetry and expected stock returns. Verrecchia (2001); and Gul and Qiu, (2002) tested the relationship between information asymmetry and corporate governance and found that higher corporate disclosure, reduces information asymmetry.

\section{Methodology and Data}

The study focuses on the secondary segment of the Nigerian capital market, relying on the Nigerian stock exchange daily closed All-Share Index (ASI) from 3 January 2000 to 29 November 2016, translating into 4167 observations. The data, in the course of this study reflected information available in the market during the period of study, and also reflected the response of market participants to information in the market during the period of study. The ASI is tested using descriptive statistics to obtain the mean, variance, skewedness, kurtosis; characteristics of the stock behavior. Further diagnostic tests were carried out to test the: normality, linearity, autocorrelation, and heteroskedasticity of the data to confirm if the statistical characteristics of the ASI are a best fit for the GARCH models used. The various GARCH models were tested to select the best in terms of the lowest value of the Akaike information Shibata, Hannan-Quinn, and Schwarz criteria employed. The economic literature shows that the GARCH specification by Bollerslev (1986) and their large extensions including EGARCH, GJR-GARCH, and APARCH will be tested among which the best will be used by the study. The parameters will be estimated using Maximum Likelihood Estimation under Gaussian, Student's t, GED, and Skewed Student distributions. The study used an OxMetrics computer econometric package to analyze the data. The first step is to take the difference of the level data (return). This is followed by applying Autoregressive order 1 AR (1) to determine the level of autocorrelation between the current and past returns. The return is squared in order to estimate the volatility.

Model Specification: The models for the various asymmetric ARCH/GARCH are specified in table 3.1 below. The table 1 also specified the GED distribution for the APARCH model.

Table 1: Asymmetric Models and GED under APARCH model

\begin{tabular}{|c|c|c|c|}
\hline & EGARCH Model & GJR-GARCH Model & APARCH Model \\
\hline Return & $R_{t}=\ln \left[P_{t} / P_{t-1}\right]$ & $R_{t}=\ln \left[P_{t} / P_{t-1}\right]$ & $R_{t}=\ln \left[P_{t} / P_{t-1}\right]$ \\
\hline Mean Equation & $\begin{array}{l}R_{t}=E\left(R_{t} \mid \Omega_{t-1}\right)+\varepsilon_{t}, \quad \mathrm{t}=1, \\
2, \ldots \mathrm{T}\end{array}$ & $\begin{array}{l}R_{t}=E\left(R_{t} \mid \Omega_{t-1}\right)+\varepsilon_{t} \\
\mathrm{~T}=1,2, \ldots \mathrm{T}\end{array}$ & $\begin{array}{l}R_{t}=E\left(R_{t} \mid \Omega_{t-1}\right)+\varepsilon_{t}, \quad \mathrm{t}=1,2, \\
\ldots \mathrm{T}\end{array}$ \\
\hline $\operatorname{AR}(1)$ & $\begin{array}{c}R_{t}=\mu+\tau_{1} R_{t-1}+\varepsilon_{t} \\
\mathrm{t}=0, \pm 1, \pm 2, \ldots, \mathrm{T}\end{array}$ & $\begin{array}{c}R_{t}=\mu+\tau_{1} R_{t-1}+\varepsilon_{t} \\
\mathrm{t}=0, \pm 1, \pm 2, \ldots, \mathrm{T}\end{array}$ & $\begin{array}{c}R_{t}=\mu+\tau_{1} R_{t-1}+\varepsilon_{t} \\
\mathrm{t}=0, \pm 1, \pm 2, \ldots, \mathrm{T}\end{array}$ \\
\hline ARMA & $\begin{array}{l}R_{t} \\
=\mu \\
+\sum_{i=1}^{p} \tau_{1} R_{t-i}+\sum_{i=j}^{q} \lambda_{1} \varepsilon_{t+} \varepsilon_{t}\end{array}$ & $\begin{array}{l}R_{t} \\
=\mu \\
+\sum_{i=1}^{p} \tau_{1} R_{t-i}+\sum_{i=j}^{q} \lambda_{1} \varepsilon_{t+} \varepsilon_{t}\end{array}$ & $\begin{aligned} R_{t}=\mu+\sum_{i=1}^{p} \tau_{1} R_{t-i} & \\
& +\sum_{i=j}^{q} \lambda_{1} \varepsilon_{t+} \varepsilon_{t}\end{aligned}$ \\
\hline $\begin{array}{l}\varepsilon_{\mathrm{t}} \\
\text { Symmetric } \\
\text { volatility }\end{array}$ & $\begin{array}{c}\sigma_{t} z_{t} ; z_{t} \sim N(0,1, v) \\
\sigma_{t}^{2}=\omega+\alpha_{i} \varepsilon_{t-1}^{2}+\beta_{i} \sigma_{t-1}^{2}\end{array}$ & $\begin{array}{c}\sigma_{t} z_{t} ; z_{t} \sim N(0,1, v) \\
\sigma_{t}^{2}=\omega+\alpha_{i} \varepsilon_{t-1}^{2}+\beta_{i} \sigma_{t-1}^{2}\end{array}$ & $\begin{array}{c}\sigma_{t} z_{t} ; z_{t} \sim N(0,1, v) \\
\sigma_{t}^{2}=\omega+\alpha_{i} \varepsilon_{t-1}^{2}+\beta_{i} \sigma_{t-1}^{2}\end{array}$ \\
\hline Asymmetric & $\ln \left(\sigma_{t}^{2}\right)$ & 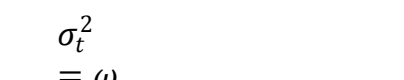 & $\sigma_{t}^{\delta} \quad q$ \\
\hline & $+\gamma_{i} \frac{\varepsilon_{t-1}}{\sigma_{t-1}^{2}}+\beta_{i} \ln \left(\sigma_{t-1}^{2}\right)$ & $+\gamma_{i}\left(\max \left(o, \varepsilon_{t-j}\right)\right]^{2}$ & $+\sum_{i=1}^{p} \beta_{t-i}\left(\sigma_{t-i}\right)^{\delta}$ \\
\hline
\end{tabular}

MODEL

Distribution

APARCH 
GED

$$
\begin{aligned}
& f(x, \mu, \sigma, v)=\frac{v}{\lambda 2\left(\frac{v+1}{v}\right) \Gamma\left(\frac{1}{v}\right)} \exp \left[-\frac{1}{2}\left|\frac{x-\mu}{\lambda \sigma}\right|^{v}\right] \text { where } \quad \lambda=\left[\frac{2 v^{-2} \Gamma\left(\frac{1}{v}\right)}{\Gamma\left(\frac{3}{v}\right)}\right]^{\frac{1}{2}}, \\
& \mu, \sigma>0, v>0 \text { are location, scale, and shape, parameters respectively. }
\end{aligned}
$$

Table 2: Definitions of Variables and Parameters for estimating Conditional Mean Models

\begin{tabular}{ll}
\hline Parameters \& variables & Definition of parameters and variables \\
\hline $\operatorname{AR}(1)$ & Autoregressive of lag order 1 \\
$\operatorname{ARMA}(\mathrm{p}, \mathrm{q})$ & Autoregressive Moving Average of lag order $(\mathrm{p}, \mathrm{q})$ \\
$R_{t}$ & Daily stock market return of All-share Index at time t \\
$\mu$, & Constant/mean average/intercept \\
$\tau_{1}$, & Coefficients of the lag returns \\
$R_{t-1}$ & Lag Return accounting for autocorrelation at time t-1 \\
$\Omega_{\mathrm{t}-1}$ & Information set at time t \\
$\alpha_{1}$, & Autoregressive coefficient \\
$\beta_{1}$, & Moving average coefficient \\
$\varepsilon_{t}$ & Error term /residual/innovation/stochastic error \\
\hline
\end{tabular}

Table 3: Parameters and Variables for Estimating Conditional Volatility Models

\begin{tabular}{ll}
\hline $\begin{array}{l}\text { Parameters \& } \\
\text { variables }\end{array}$ & Definition of parameters and variables \\
\hline Ln & Natural Logarithm \\
$\sigma^{2}$ & Conditional variance \\
$\ln \left(\sigma_{t}^{2}\right)$ & Log conditional variance \\
$\omega$ & Constant \\
$\alpha_{t}$ & Coefficient of arch term. It measures the magnitude of the shocks of the news or \\
$\varepsilon_{t-1}^{2}$ & measures the symmetric effects of the last period shocks on current volatility \\
$\beta_{i}$ & Arch term, squared error term at time t-1 \\
$\sigma_{t-1}^{2}$ & Parameter that measures persistence in the conditional variance \\
$\varepsilon_{t-1}$ & Garch term, squared conditional variance at time t -1 \\
$\gamma_{i}$ & Lagged error term \\
$\left|\varepsilon_{t-1}\right|$ & Asymmetry or leverage effect coefficient \\
$v$ & Absolute value of the standardized residuals \\
$\delta$ & Degree of freedom \\
\hline
\end{tabular}

\section{Returns}

Measurement of Daily Market Returns: The daily closed index is transformed by taking its difference to enable us obtain a change and then purge the data series from the presence of unit roots. This is expressed in natural log form shown in Table 1, where the logarithm of stock market index at period $t\left(P_{t}\right)$ is related to the index at period $t$-1and expressed by $R_{t}=\ln \left(P_{t} / P_{t-1}\right)$, where: $R_{t}$ is a time series return on daily closed index at time $t$, and $\ln$ is the natural log of the daily market index.

Estimating Conditional Mean: The mean equation is given by $R_{t}=E\left(R_{t} \mid \Omega_{t-1}\right)+\varepsilon_{t}$ as indicated in Table 1 , where $\mathrm{E}\left(. \mid\right.$.) denotes the conditional expectation operator, $\Omega_{\mathrm{t}-1}$ is the information set available at $\mathrm{t}-1 . \varepsilon_{t}$ are the random innovations (surprises) with zero mean and constant variance. The autoregressive of first order 1 $\operatorname{AR}(1)$ of returns is also expressed as $R_{t}=\mu+\tau_{1} R_{t-1}+\varepsilon_{t} ; \mathrm{t}=1,2, \ldots, \mathrm{T}$, where $\tau_{1}$, is the lag return coefficient, and $R_{t-1}$ is the previous year return. Also, ARMA (p,q) process of autoregressive order $\mathrm{p}$ and moving average order $\mathrm{q}$ is described as $R_{t}=\mu+\sum_{i=1}^{p} \alpha_{1} R_{t-i}+\sum_{i=j}^{q} \beta_{1} \varepsilon_{t+} \varepsilon_{t}$. The ARMA mean equation model can be expressed in polynomials of degree $\mathrm{n}, \mathrm{p}$ and q using backshift operator $B$ as $R_{t}=\mu+\alpha(B) R_{t}+$ $\beta(B) \varepsilon_{t}$.We have a perfect autoregressive process if $\mathrm{q}=0$ while we have pure moving average process if $\mathrm{p}=0$. 


\section{Conditional Variance}

Conditional Variance (Symmetric Volatility): Engle (1982) pioneered the Autoregressive Conditional Heteroscedasticity (ARCH) process where he defined the error term in the mean returns $\left(\varepsilon_{t}\right)$ as the innovation of the process of the form $\varepsilon_{t}=z_{t} \sigma_{t}$, where $z_{t} \sim N(0,1) \cdot z_{t}$ is an independently identically distributed (i.i.d) process with $\mathrm{E}\left(z_{t}\right)=0$ and $\operatorname{var}\left(z_{t}\right)=1$. The Engle (1982) ARCH model is a linear function of the lagged value of the innovations as $\sigma_{t}^{2}=\omega+\sum_{i-1}^{q} \alpha_{i} \varepsilon_{t-1}^{2}$. However, ARCH required many parameters and a high order $\mathrm{q}$ to capture the volatility process. Hence, Bollerslev (1986) generalized ARCH (GARCH) by importing the lag of residual variance to reduce the number of estimated parameters and imposing nonlinear restrictions. The Bollerslev (1986) Generalized Autoregressive Conditional Heteroskedasticity (GARCH) model is of the form $\sigma_{t}^{2}=\omega+\alpha_{i} \varepsilon_{t-1}^{2}+\beta_{i} \sigma_{t-1}^{2}$. To ensure that $\sigma_{t}^{2}$ is positive for all $t$. Bollerslev (1986) imposed these restrictions $\omega>0, \alpha_{i} \geq 0,($ for $i=1,2, \ldots, q)$, and $\beta_{i} \geq 0($ for $j=1,2, \ldots, p)$. The $\sigma_{t}^{2}$ represents the conditional variance of ASI at time $t, \omega$ is the intercept, while $\alpha_{i}$ is a coefficient (the symmetric effect of the model) which measures the recent or short-term effects of news on stock volatility. Put in another way, $\alpha_{i}$ can be referred to as a first order ARCH term which transmits news about volatility from the previous period. The $\varepsilon_{t-1}^{2}$ is the ARCH term this is typically interpreted as the measures of the impact of recent news on volatility. $\beta_{i}$ is the coefficient of autoregressive component of conditional variance which can be interpreted as persistent coefficient that measures the impact of the old news on volatility or the first order GARCH term and $\sigma_{t-1}^{2}$ is the GARCH term that measures the long term effect of news on stock volatility.

Asymmetric Volatility: To capture the asymmetric volatility in the stock market returns, we tested EGARCH model by Nelson (1991); GJR-GARCH model by Glosten Jaganathan, and Runkle (1993); and APARCH model by Ding et al. (1993) with normal, Student's t, GED, and Skewed distributions. Nelson (1991) introduced EGARCH as an extension to the GARCH model proposed by Bollerslev (1986) to overcome some weaknesses related to the GARCH model in handling financial time series (Wallenius, Fedorova, and Collan, 2013). Nelson's EGARCH model is also superior to Bollerslev's GARCH model for studying the impact of shocks on stock and is widely used for estimating volatility in financial markets because it applies logged conditional variances and if the model parameters have negative values, the conditional variance remains positive and does not require artificial imposition of non-negativity constraints on the model parameters. From table 1 (above), the asymmetric volatility EGARCH equation is stated as $\log$ of the conditional variance $\left\{\ln \left(\sigma_{t}^{2}\right)\right\}$. There are four parameters to be estimated: $\omega, \alpha_{i}, \gamma_{i}, \beta_{i}$ where $\omega, \alpha_{i}, \beta_{i}$ are as previously defined, while the coefficient $\gamma_{i}$ measures the asymmetric effect or leverage effect of the shocks on volatility. The presence of asymmetric effects can be tested by the hypothesis that $\gamma_{i}=0$. if $\gamma_{i}=0$, it implies a symmetric effect where positive and negative shocks of the same magnitude have the same effect on volatility of stock returns. The effect is asymmetric if $\gamma_{i} \neq 0$. If $\gamma<0$, (negative and significant) then, positive shock (good news) generate less volatility than negative shocks (bad news). When $\gamma>0$, (positive and significant), it signifies that positive innovations are more destabilizing than negative innovations (Atoi, 2014). The total impact of good news on volatility is measured by $|1+\gamma| \varepsilon_{t-1} \mid$, while the total impact of bad news is measured as $|1-\gamma| \varepsilon_{t-1} \mid$.

\section{Empirical Results}

Descriptive Statistics: The descriptive statistical characteristics of the daily market index returns showed average daily returns of $0.04 \%$; compared to a very high average daily risk of $1.123 \%$ as measured by standard deviation which indicates that the stock returns in Nigeria are characterized by higher volatility. Thus, it is established that the higher the risk, the higher the volatility and the lower the returns in Nigerian stock market. The third and fourth moments as measured by skewedness and kurtosis also exhibit asymptotic and leptokurtic (fat-tailed) behavior where the degree of asymmetry distribution around the mean is 0.19 which is greater than zero for normal distribution. The kurtosis stood at 26.14 , greater than the normal standard of 3.0. However, under normal distribution, R-square is expected to be greater than $60 \%$ but in this study it stood at $9 \%$ while the F-Statistics was positive (412.74) and significant at $1 \%$ level. Overall, the descriptive statistics behavior of the stock market returns in Nigeria is not normally distributed. This is shown in Table 4 below

More importantly, when applying residual diagnostic tests, the normality test by Jacque-Berra rejects the null hypothesis of normal distribution which is positive at 92987.14 and significant at 1 per cent level. The 
heteroskedasticity test or ARCH-LM test also accepts the alternative hypothesis of the presence of ARCH effect in the stock market returns while the BDS test rejects the null hypothesis of linearity in the distribution of the stock market returns. The ADF exhibited no unit root in the data while the serial correlation results reject the null hypothesis of the presence of serial correlation of market returns. In summary, the behavior of stock market returns in Nigeria is nor-normal, non-linear, auto-correlated, and heteroskedastic (ARCH effect). Therefore, the best models fit for this behavior of stock returns are the ARCH/GARCH family with their higher extensions. However, the movement of market index and its corresponding first difference data is demonstrated in figure 1 (below):

Table 4: Descriptive characteristics of Stock Market Returns in Nigeria

\begin{tabular}{lllllllllllll}
\hline Mean & $\begin{array}{l}\text { Std. } \\
\text { Dev }\end{array}$ & $\begin{array}{l}\text { Skewed } \\
\text { ness }\end{array}$ & Kurtosis & R-Sq & JB & Q-Stat & ADF & BDS & $\begin{array}{l}\text { ARCH } \\
\text { LM }\end{array}$ & F-Stat & BJ & $\begin{array}{l}\text { Obser } \\
\text { vations }\end{array}$ \\
\hline 0.0004 & 0.01123 & 0.1942 & 26.14 & 0.090 & $92987.14^{*}$ & $651.92^{*}$ & $-35.57^{*}$ & 0.054 & $795.51^{*}$ & $412.74^{*}$ & $44.75^{*}$ & 4168 \\
& & & & & & & & & & & & \\
p-value & & & & & 0.0000 & 0.0000 & 0.0000 & 0.000 & 0.0000 & 0.0000 & 0.0000 & \\
\hline
\end{tabular}

Note that std Dev, JB, Q-Stat, BDS, ADF, BJ, and ARCH are standard deviation, Jarque-Bera, correlogram, Brock-DechertScheikman, Augmented-Dickey-Fuller, Box Jerkins, and Heteroskedasticity statistics respectively; while * implies significance level at 1 percent.

Source: Omokehinde, Abata, Somoye, and Migiro (2017)

\section{Figure 1: Daily Movement in the NSE-All-Share Index from 3 Jan. 2000- 29 Nov 2016}

\section{NSE ALL-SHARE INDEX 2000- 2016}

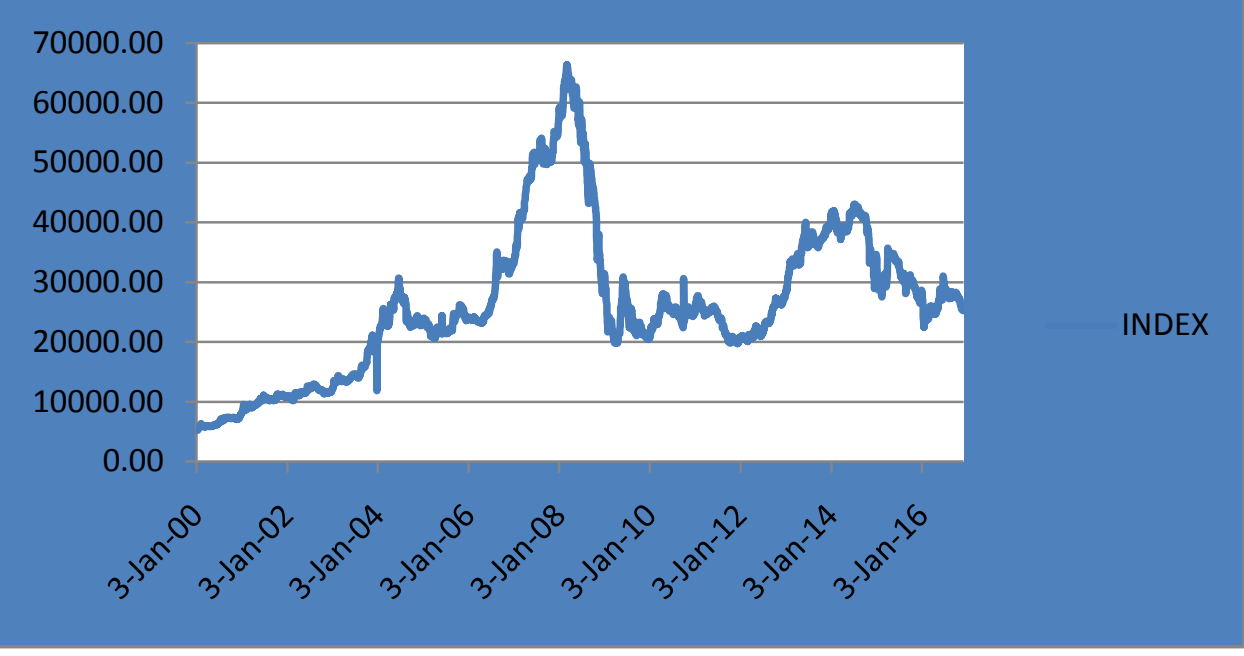

The daily movement of Nigerian stock market index at level form over the period $3^{\text {rd }}$ January 2000 to 29 November 2016is shown in figure 4.1 above. The study revealed that the behavior of the daily index exhibits a random walk movement (RWM). The index grew by $478.55 \%$ to peak at 30,703.46 on June 18, 2004 from its beginning level of 5,306.99. The bank recapitalization news came as a surprise to the participants in the market and declined the index by $32.71 \%$ to 20,661.44 on 6 April 2005 from its first peak level. However, the success of bank recapitalization coupled with indiscriminate grating of margin facility for the acquisition of shares had driven the index to an all-time high of $66,286.58$ on 4 March 2008 , a growth of $220.82 \%$. The global financial crisis in 2008 drove the index down by $-70.12 \%$ to $19,803.60$ a year after on 4 March 2009 . The index has not yet fully recovered to the level it was at on4 March 2008. The index has been persistently hovering between 20,000 and 40,000 level since 2009 and finally stood at 25, 318.41 on 29 November2016. However, the peculiar characteristic of the index as shown in Figure 4.1 is that it is white noised. This characteristic is noted in most integrated level zero, (I(0)) variables and that is why they have to be differenced. Thus, the movement of the differenced index which is referred to stock market return is shown in figure 4.2 below: 
Meanwhile, a careful look at figure 2 (above) shows that returns fluctuate around the mean value and the RWM does not emerge again after the index has been transformed to first difference or return. The fluctuations are both in the positive and negative region with clustering in volatile periods alternated by periods of calm. Hence, the stock market return is clustering or pooling with large shocks of both signs following large shocks while small shocks of both signs following small shocks is consistent with the findings of Mandelbrot (1963). This suggests that the residual is conditionally heteroskedastic and it can be represented by ARCH and GARCH models. In addition, the variance of the stock returns is not constant over time but time-varying with evidence of volatility clustering and persistence being consistent with the findings of Bollerslev (1986), Engle (1982) and Nelson (1994). There are occasional outliers induced by fundamental financial crises. In short, the Nigerian stock market return has a property of covariance stationarity or reversibility, the return is chaotic rather than martingale in nature. The sudden astronomical increase in stock market index that was witnessed in period of 2007 and 2008 is believed to have been occasioned by the recapitalization in the banking sector, the indiscriminate granting of margin facilities by financial institutions, and the lingering effect of the global financial crisis that erupted in the world capital markets including the Nigerian stock market between 2008 and 2016.

Figure 2: Daily Movement of Stock-Market Return (4 Jan, 2000 to 29Nov, 2016)

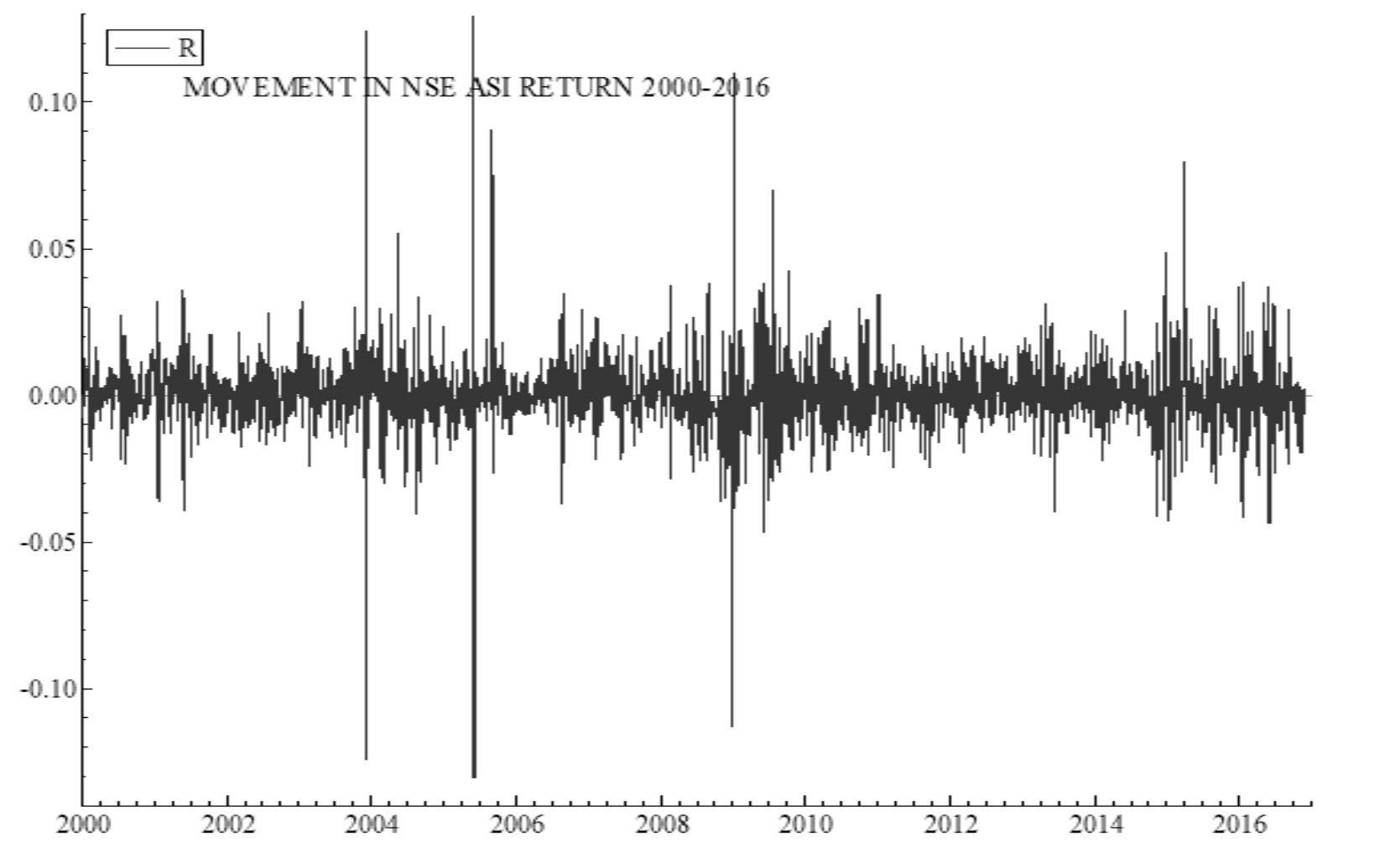

No of Years

The choice of APARCH $(1,1)$ model as the best fit from between the most two preferred asymmetric GARCH models is taken using the four distribution criteria: normal, student-t, GED, and Skewed-t. However, the GED distribution is considered to be the most efficient because it has the larger log likelihood of 34295.9 with the lowest Shibata Information Criterion of -16.457859as shown in table 5 below: 
Table 5: Selection of the Best-Fit Model

\begin{tabular}{lllllll}
\hline CRITERION & \multicolumn{2}{l}{ GJR-GARCH MODEL } & & \multicolumn{4}{l}{ APARCH MODEL } \\
& Student-t & GED & Skewed & Student-t & GED & Skewed \\
\hline Log likelihood & 32765 & 34159.1 & 32839.1 & 32902.2 & $\mathbf{3 4 2 9 5 . 9}$ & 33021.2 \\
AIC & -15.723521 & -16.392636 & -15.758607 & -15788905 & $\mathbf{- 1 6 . 4 5 7 8 5 4}$ & -15.845552 \\
SIC & -15.715920 & -16.385035 & -15.749485 & -15.779784 & $\mathbf{- 1 6 . 4 4 8 7 3 3}$ & -15.834910 \\
Shibata & -15.723524 & -16.392639 & -15.758611 & -15788909 & $\mathbf{- 1 6 . 4 5 7 8 5 9}$ & -15845558 \\
Hannan-Quinn & -15.720832 & -16.389948 & -15.755380 & -15.785679 & $\mathbf{- 1 6 . 4 5 4 6 2 8}$ & -15.841788 \\
\hline
\end{tabular}

Source: Omokehinde, Abata, Somoye, and Migiro (2017)

The asymmetric and leverage effects measured by the nonlinear asymmetric variance specifications have been pruned down to GJR-GARCH and APARCH models where APARCH $(1,1)$ model under the GED distribution has been finally selected for the analysis of the results as shown in table 6 below:

Table 6: APARCH (1,1) Approach under GED Distribution

\begin{tabular}{lllll}
\hline & Coefficient & Std.Error & t-value & t-prob \\
\hline $\operatorname{Cst}(\omega)$ & 100.000000 & 21.500 & 4.651 & 0.0000 \\
ARCH $(\alpha)$ & 1.000000 & 0.086582 & 11.55 & 0.0000 \\
GARCH $(\beta)$ & 0.695950 & 0.069905 & 9.956 & 0.0000 \\
APARCH $(\gamma)$ & -1.000000 & 0.27675 & -3.613 & 0.0003 \\
APARCH $(\delta)$ & 0.920859 & 0.062108 & 14.83 & 0.0000 \\
G.E.D.(DF) & 0.174637 & 0.011093 & 15.74 & 0.0000 \\
\hline Source 0
\end{tabular}

Source: Omokehinde, Abata, Somoye, and Migiro (2017)

Table 6 (above) revealed the effect of asymmetric information on the volatility of stock returns in the Nigerian stock market from 3 January 2000 to 29 November 2016. The asymmetric parameter of interest is measured by APARCH gamma $(\gamma)$. The coefficient is negative $(-1.000)$ and statistically significant at $1 \%$ level. This confirms that there is an asymmetric or leverage effect where bad news has a destabilizing effect on volatility in Nigeria. The total impact of bad news on volatility is explosive at 2.0 during the period. Also, the volatility persistence which is measured by the sum of $\operatorname{ARCH}(\alpha)$ and $\operatorname{GARCH}(\beta)$ stood at 1.695950. This is above unity and suggests that it takes the volatility long time to attenuate in Nigeria. This could largely be ascribed to the persistent effect of the 2008 global financial crisis which probably has eroded investors' confidence in the market. However, the use of the ARMA $(1,1)$-APARCH $(1,1)$ model provides a less significant result relative to APARCH $(1,1)$, model as shown in table 7 below.

Table 7: ARMA (1,1)-APARCH (1,1) Approach under GED Distribution

\begin{tabular}{lllll}
\hline & Coefficient & Std.Error & t-value & t-prob \\
\hline $\mathrm{Mu}$ & 5.167942 & 1.7948 & 2.879 & 0.0040 \\
$\mathrm{AR}(1)$ & 0.432953 & 0.089028 & 4.863 & 0.0000 \\
$\mathrm{MA}(1)$ & -0.077414 & 0.13170 & -0.5878 & 0.5567 \\
$\mathrm{Cst} .(\omega)$ & 1.626415 & 1.7062 & 0.9532 & 0.3405 \\
$\mathrm{ARCH}(\alpha)$ & 0.298091 & 0.051768 & 5.758 & 0.0000 \\
GARCH $(\beta)$ & 0.648582 & 0.079763 & 8.131 & 0.0000 \\
APARCH $(\gamma)$ & -0.050815 & 0.055587 & -0.9141 & 0.3607 \\
APARCH $(\delta)$ & 1.419660 & 0.25090 & 5.658 & 0.0000 \\
G.E.D. $(D F)$ & 1.115214 & 0.060295 & 18.50 & 0.0000 \\
\hline
\end{tabular}

Source: Omokehinde, Abata, Somoye, and Migiro (2017)

The application of ARMA (1,1)-APARCH $(1,1)$ approach as indicated in Table 7 (above), showed that the autoregressive order $1, \operatorname{AR}(1)$ parameter is positive and significant at $1 \%$ level which is different from the moving average order $1 \mathrm{MA}(1)$ with a negative coefficient and insignificant probability value. Thus, the present return of the Nigerian stock market has $43.30 \%$ predictive probability dependence on the previous level of returns. Also, the asymmetric coefficient (Gamma1), although negative, is insignificant. The distribution is less significant, relative to APARCH $(1,1)$ as shown in Table 4.32 (above). Other parameters of ARCH and GARCH were positively and significantly distributed but with less persistent volatility of 0.946673 
(approximately 1) signifying that stock returns volatility persistence will take longer to decay in Nigerian stock market. Also the evidence of asymmetric volatility is confirmed in the Nigerian stock market with negative coefficient of Gamma1 (-0.050815) which suggests that bad news innovations are more destabilizing with volatility of stock returns. However, the total impact of news on volatility using this approach is 1.050815 which is 0.949185 lower than when using the APARCH $(1,1)$ approach.

\section{Conclusion and Recommendations}

The paper concluded that asymmetric or leverage effect exists in the Nigerian stock market. The impact of bad news has more disturbing effect on volatility than good news. The evidence of asymmetry in the Nigerian stock market therefore suggests that information usually enter the market non-linearly in such a way that returns were nor-normally distributed, thereby, modified the variance of the error term to be time-varying instead of being constant as in a perfect market. The existence of asymmetric information indicates that the Nigerian stock market is informational in efficient. The volatility persistence was more explosive and above unity which suggests that it takes volatility persistence long to decay. That is why the 2008 global financial crisis is still persisting in the market to date, accounted for the investors' sentiments of loss of confidence in the market and their preference for investing in fixed income securities and real estate. It is therefore, recommended that the Nigerian stock market should be deepened and diversified to include trading in financial derivatives instruments with a view to boosting investors' confidence already weakened by the longer period it takes volatility persistence to decay. Financial regulators should operate a deep, efficient and uninterrupted information flows framework to reduce the effect of information asymmetry on investment decisions, increase transparency, and boost investors' confidence in the Nigerian stock market.

\section{References}

Abad, D. \& Rubia, A. (2005). Estimating the Probability of Informed Trading: Further Evidence from an Orderdriven Market. Journal of Financial Economics, 7, 1-37

Akerlof, G. A. (1970). The Market for Lemons: Quantitative Uncertainty and the Market Mechanism. The Quarterly Journal of Economics, 84(3), 488-500.

Alberg, D., Shalit, H. \& Yosef, R. (2008). Estimating Stock Market Volatility using symmetric ARCH Models. Applied Financial Economics, 18, 1201-1208.

Atoi, N. V. (2014). Testing volatility in Nigeria stock market using GARCH models. Central Bank of Nigeria: Journal of Applied Statistics, 5(2), 65-93.

Ayadi, O. (1984). The Ramdom Walk Hypothesis and the Behaviour of Share Price in Nigeria. Nigerian Journal of Social Studies, 26(1), 14-27.

Bachelier, L. J. (1900). Théorie de la spéculation. Annales. Scientifiques de L'E'cole Normale Supe'rieurese'r, $3(17), 21-86$.

Black, F. (1976). Studies in stock price volatility changes, Proceedings of the 1976 Business Meeting of the Business and Economic Statistics Section. American Statistical Association, 177-181.

Bollerslev, T. (1986). Generalized Autoregressive Conditional Heteroscedasticity, Journal of Econometrics, 31(3), 307-327.

Chen, N. F., Rott, R. \& Ross S. A. (1986). Economic Forces and the Stock Market. The Journal of Business, 59(3), 383-403.

Clarke, J. \& Shastri, K. (2000). On Information Asymmetry Metrics. Working Paper, Katz Graduate School of Business, University of Pittsburgh.

Ding, Z., Granger, C. W. J. \& Engle, R. F. (1993). A Long-Memory Property of Stock Market Returns and a New Model. Journal of Empirical Finance, 1, 83-106.

Easley, D. \& O'Hara, M. (2004). Information and the cost of Capital. The Journal of Finance, 59,1553-1583. http://dx.doi.org/10.1111/j.1540-6261.2004.00672.x

Engle, R. F. (1982). Autoregressive Conditional Heteroskedascity with Estimates of the Variances of U.K. Inflation. Econometirica, 50(4), 987-1007.

Engle, R. F. \& Ng, V. K. (1993). Measuring and Testing the Impact of News on Volatility, Journal of Finance, 48, 1749-78.

Fama, E. F. (1970). Efficient Capital Markets: A Review of Theory and Empirical Work. Journal of Finance, 2, 383-417. 
Fama, E. F. \& French, K. R. (1993). Common risk factors in the returns on stocks and bonds. Journal of financial economics, 33(1), 3-56.

Fama, E. F. \& French, K. R. (2015). A five factor asset pricing model, Journal of Financial Economics, 166(1), 122.

Gauss, C. F. (1821). Theoria combination is observationum erroribus minimis obnoxiae, Parts 1,2 \& supplement Werke, 4, 1-108.

Glosten, L. R., Jaganathan, R. \& Runkle, D. (1993). On the relationship between the expected value and the volatility of the nominal excess return on stocks. Journal of Finance, 48(5), 1779-1801

Gul, F. A. \& Qiu, H. (2002). Legal Protection, Corporate Governance and Information Asymmetry in Emerging Financial Markets. http:/www.ssrn.com

Kendall, M. (1953). The Analysis of Economic Time Series - Part 1: Prices. Journal of the Royal statistical Society, Series A, 116(1), 1-34.

Levi, S. \& Zhang, X. J. (2008). Information Asymmetric and the Increase in Expected Stock Returns before Earnings Announcements. Working Paper

Lintner, J. (1965). The Valuation of Risk Assets and the Selection of Risky Investments in Stock Portfolios and Capital Budgets. The Review of Economics and Statistics, 47(1), 13-37.

Mandelbrot, B. (1963). The variation of certain speculative prices. Journal of Business, 36(4), 394 - 419.

Markowitz, H. (1952) Portfolio Selection. The Journal of Finance, 7(1), 77-91.

MSCI BARRA. (2013). MSCI Long-Short BARRA Factor Indexes. Retrieved from http://www.msci.com/.../MSCI_Barra_Factor_\%20indices_Methodology_Nov.13.Pdf

Nelson, D. B. (1991). Conditional Heteroskedasticity in Asset Returns: A New Approach. Econometrica, 59(2), 347-370.

Ross, S. A. (1976). The Arbitrage Theory of Capital Asset Pricing. Journal of Economic Theory, 13(3), 341-360.

Sharpe, W. F. (1964). Capital Asset Prices: A Theory of market Equilibrium under Conditions of Risk. Journal of Finance, 19(3), 425-442.

Stiglitz, J. \& Walsh, C. (2002). Economics. New York, London. Norton

Stiglitz, J. E. (2003). Information and the Change in the Paradigm in Economics: Part 1. American Economist, 47(2), 6-21

Strong, R. A. (2004). Practical Investment Management, Thomson South-Western, Third Edition, University of Maine.

Verrechia, R. E. (2001). Essays on Disclosure. Journal of Accounting and Economics, 32, 97-80

Wallenius, L., Fedorova, E. \& Collan, M. (2013). Surprise effect of European macroeconomic announcements on CIVETS stock markets", mimeo, School of Business, Lappeenranta University of Technology, Finland

Wang, Z., Kutan, A. M. \& Yang, J. (2005). Information Flows within and across Sectors in Chinese Stock Markets. Quarterly Review of Economics and Finance, 45(5), 767-780. http://dx.doi.org/10.1016/j.qref.2003.08.001

Wold, H. O. (1939). A Study in the Analysis of Stationary Time Series. Journal of the Royal Statistical Society, 102(2), 295-298.

Zakoian, J. M. (1994). Threshold Heteroskedastic Models. Journal of Economic Dynamics and Control, 18(5), 931-955. 